\title{
REFLEXÕES SOBRE AS INTERFACES ENTRE DISCURSO, FORMAÇÃO DE PROFESSOR E ENSINO: O RELATÓRIO DE ESTÁGIO SUPERVISIONADO
}

\section{REFLECTIONS ON INTERFACES BETWEEN SPEECH, TEACHER TRAINING AND TEACHING: THE SUPERVISED STAGE REPORT}

\author{
Sandro Luis da Silva ${ }^{24}$
}

\begin{abstract}
RESUMO: Este artigo tem por objetivo trazer reflexões sobre as interfaces entre discurso, formação de professor e escrita do relatório de estágio supervisionado. Por meio de uma abordagem qualitativa, apresenta-se uma análise documental, quatro relatórios de estágio de alunos da licenciatura em português, de uma universidade pública federal. Procura-se evidenciar o olhar que os sujeitos enunciadores têm em relação ao estágio refletindo a constituição do ethos discursivos deles. A base teórica para o estudo pauta-se em Maingueneau $(2011,2015)$ no tocante ao discurso e ao ethos discursivo. No tocante ao relatório de estágio, a análise volta-se para Silva (2012) e Silva, Gonçalves e Melo (2013). Esses resultados corroboram a tese, defendida neste artigo, de que o discurso pedagógico - e mais especificamente o do relatório de estágio, simploriamente ou equivocadamente considerado como mero documento de registro ou como texto meramente descritivo ou relato de atividades desenvolvidas durante o estágio é constitutivamente marcado pela argumentatividade, a qual se caracteriza como uma categoria para evidenciar o ethos discursivo do enunciador.
\end{abstract}

PALAVRAS-CHAVE: Discurso. Ethos discursivo. Formação do professor. Estágio supervisionado.

ABSTRACT: This article aims to bring reflections on the interfaces between speech, teacher training and written supervised stage report. Through a qualitative approach, a documentary analysis is presented, four reports of internships of students of the licentiate in Portuguese, of a federal public university. It seeks to highlight the view that the enunciating subjects have in relation to the stage reflecting the constitution of their discursive ethos. The theoretical basis for the study is based on Maingueneau $(2011,2015)$ in discourse and the discursive ethos. Regarding the internship report, the analysis turns to Silva (2012) and Silva, Gonçalves e Melo (2013). These results corroborate the thesis that the pedagogical discourse - and more specifically that of the internship report, simpler or mistakenly considered as a mere registration document or as merely descriptive text or report of activities developed during the internship - is constitutively marked by argumentativeness, which constitutes a category of constitution of the discursive ethos of the enunciator.

KEYWORDS: Discourse. Discursive ethos. Teacher training. Supervised internship.

\section{Considerações iniciais}

Há três anos tenho me interessado pelo discurso pedagógico, mais especificamente aquele presente nos cursos universitários na área de formação de professor. Venho trabalhando com dois gêneros discursivos específicos: o memorial de leitura e relatório de estágio supervisionado, resultado da unidade curricular que ministro - Língua, Literatura e Ensino: Fundamentos I, II e III e da função de supervisor de Estágio Supervisionado Curricular de Português I, II e III no Departamento de Letras da Universidade Federal de São Paulo. Essa atividade profissional tem me oferecido um material bastante rico para refletir sobre o discurso pedagógico, a formação inicial do professor de língua portuguesa e a constituição do ethos discursivo.

O foco da pesquisa que venho desenvolvendo concentra-se na análise de discursos que circulam no espaço acadêmico, mais especificamente em relatórios de estágio supervisionado

\footnotetext{
${ }^{24}$ Professor Adjunto III do Departamento de Letras e do Programa de Pós-Graduação em Letras - Mestrado Acadêmico - da Universidade Federal de São Paulo (UNIFESP). E-mail: sandro.luis2602@gmail.com
} 
de língua portuguesa, resenhas, relatório de autoavaliação de estudantes do curso de Letras. Restrinjo meu olhar para o discurso pedagógico, em virtude da próxima e intrínseca relação que possuo com ele, possibilitando a desconstrução de algumas concepções a respeito das práticas existentes no espaço escolar, mais especificamente neste estudo, da sala de aula, materializada no gênero discursivo relatório de estágio.

No discurso pedagógico, vários são os sujeitos que o produzem - professores, alunos, diretores, coordenadores supervisores. No entanto, para este artigo, considerei o lugar de onde os sujeitos - futuros professores de língua portuguesa para o Ensino Fundamental II e Ensino Médio - se manifestam, considerando, ainda, o interdiscurso e a formação discursiva deles.

Procurei analisar o funcionamento do discurso (Orlandi, 1988), isto é, a relação da língua com a realidade dos alunos, no caso, o meio acadêmico e a prática docente na escola básica. Recuperando Pacífico (2011, p. 102), "a língua funciona como a materialidade do discurso; em outras palavras, a língua é o lugar material em que se realizam os efeitos de sentido", que caracterizam o discurso, segundo Pêcheux (1997).

Enfatizo que este estudo procura proporcionar uma reflexão que revele:

(i) as imagens que se constroem e são construídas no curso de Letras (Português) sobre os profissionais em formação e sobre o próprio curso;

(ii) os sentidos construídos sobre a sua própria formação, a partir dos discursos construídos na Universidade e fora dela, por que não;

(iii) o ethos discursivo dos estudantes de língua portuguesa e,

(iv) a imagem que construída do ensino de língua portuguesa nos relatórios de estágio.

Para atender ao que proponho neste texto, divido-o em duas grandes seções: na primeira, trago considerações sobre elementos teóricos que subsidiam a análise da escrita do relatório de estágio de quarto alunos do curso de Letras (Português), do sétimo período, apresentada na segunda parte, seguida das palavras finais e das referências.

Evidentemente que não tenho a pretensão de trazer soluções para as questões apontadas ao longo do artigo, devido a duas circunstâncias: primeiro em virtude do limite do artigo e, segundo, a própria complexidade do tema. $\mathrm{O}$ que proponho neste texto é uma reflexão sobre a formação do professor de língua portuguesa, revelada no discurso desses estudantes, de modo a contribuir para que a Universidade possa intervir positivamente na atuação desses futuros profissionais na escola de educação básica.

\section{Um pouco de teoria...}

Tratar o discurso pedagógico em um artigo me põe a pensar várias situações, sobretudo um breve percurso por que a escola tem passado nos últimos anos.

O discurso pedagógico constitui-se em uma porta de entrada para a constituição de um processo interativo entre os sujeitos, capaz de proporcionar estratégias discursivas, tendo em vista o caráter dialético, ideológico e dialógico da linguagem, o qual é apontado para a construção do conhecimento.

Há várias tentativas de se desfazer a ideia de educação bancária, que ainda está presente na maioria das escolas brasileiras. Existem, no entanto, instituições de ensino que promovem uma interação entre os sujeitos que participam do processo de ensinoaprendizagem, fazendo com que o professor exerça, de fato, o papel de mediador nas práticas pedagógicas. E esse novo fazer pedagógico, ou essa nova maneira de conduzir esse processo nos leva a rever o ethos discursivo que se constrói dos sujeitos que dele participam. 
Considero, a partir dos estudos de Maingueneau (2011, 2015), que o ethos discursivo dos sujeitos enunciadores dos relatórios pode ser construído, observando:

(i) o lugar de onde falam;

(ii) o uso das estratégias linguístico-discursivas utilizadas por eles;

(iii) os possíveis efeitos sentidos produzidos no discurso desses sujeitos;

(iv) dos sentidos atribuídos ao estágio supervisionado, e, ainda,

(v) dos sentidos atribuídos ao ensino de Língua Portuguesa.

O ethos é construído pelo discurso, no momento da enunciação. E, como aponta Maingueneau (2011), o discurso é a linguagem em ação. É pressuposto, neste texto, que a linguagem é uma construção social, em que dialogia e interação se constituem como seus elementos fundamentais. Considera-se, ainda, que a compreensão do domínio da própria autonomia discursiva também é construída na interação social que se realiza entre os sujeitos numa situação enunciativa.

O estudante universitário depara-se com uma série de gênero discursivo durante sua formação. Segundo Maingueneau (2011, p. 115), "toda atividade de linguagem pertence a um gênero de discurso". Para o autor, os gêneros são dispositivos de comunicação e estão divididos em instituídos e conversacionais. Para o linguista francês, a caracterização de um gênero apoia-se em critérios heterogêneos, de acordo com a função que irá exercer numa determinada situação enunciativa.

A partir dessa perspectiva, é possível dizer que o sujeito produz conhecimento, o qual pressupõe, também, textos escritos - e é nessa escrita que o conhecimento se manifesta, revelando a compreensão da realidade, considerando-se os elementos constitutivos do universo de relações culturais, sociais e interpessoais vivenciadas. O sujeito manifesta-se, portanto, por meio de gêneros discursivos.

No novo contexto em que se encontra o aluno - vida acadêmica - há uma mudança de perspectiva em relação à escrita: esta deixa de ter uma visão extremamente estruturalista, inflexível para a s u mir uma forma mais dinâmica, que precisa atender às necessidades de comunicação numa dada situação enunciativa. E nela também pode se valer dos recursos oferecidos pelos tecnologias digitais.

A linguagem do mundo atual privilegia modalidades diferentes da escrita, valendo-se, inclusive, dos recursos das novas tecnologias, que vêm somando novidades ao processo comunicacional. Esses eventos devem ser vistos numa nova perspectiva que acaba por caracterizar mais um dos modos de representação cultural e que contribuem decisivamente no processo comunicacional.

Nessa perspectiva, a universidade deve ser o espaço de construção do conhecimento; nela, o ideal é exigir a articulação entre teoria e prática, entre sujeito e objeto apreendido, para que o conhecimento ganhe efeito de sentido e proporcione uma formação significativa para os sujeitos. É preciso levar em consideração as experiências que os sujeitos trazem para a sala de aula.

O relatório de estágio é um dos gêneros discursivos presentes na esfera discursiva universitária, em especial nos cursos de licenciatura. Trata-se de um gênero em que "a reflexão criteriosa sobre as atividades didáticas experienciadas nos estágios, orientadas por saberes docentes de diversas naturezas", incluindo aí a mobilização da literatura científica e pode resultar "em contribuições para as futuras situações de trabalho, ou seja, para profissionalização do professor" (SILVA, 2012a, p. 288).

Ainda em relação ao relatório de estágio, há de se considerar e se espera um olhar crítico do estagiário sobre as práticas pedagógicas observadas no processo de ensinoaprendizagem da escola básica, considerando, evidentemente, o caráter profissional atribuído 
à escrita reflexiva, uma das características dos relatórios. Este gênero é caracterizado pelas confluências de escritas características de duas esferas enunciativas: acadêmica e escolar. De acordo com Melo, Gonçalves e Silva (2013, p. 98),

Da primeira, emergem práticas características do discurso acadêmico, como o diálogo com a literatura científica de referência para orientar a ação profissional. Da segunda, emergem relatos de histórias de vida envolvendo o percurso profissional do professor no magistério e discursos sobre a ação docente nas escolas de ensino básico.

O relatório do estágio vai além do registro do que se observa no contato com a escola básica. Trata-se de um gênero discursivo em que o futuro professor registra suas impressões, ações e reflexões sobre o processo de ensino-aprendizagem, conciliando teoria - vista na universidade - e a prática pedagógica realizada na escola.

\section{Contextualização da pesquisa}

Os dados para a escrita deste artigo foram obtidos com a análise documental numa perspectiva discursiva, a partir da observação dos contextos de formação de professores, neste caso, o relatório de estágio, produto desse contexto. O corpus está constituído por quatro relatórios de estágios selecionados dentre os centro e vinte e três relatórios de Estágio Supervisionado II entregues. A escolha desses textos levou em consideração o seguinte critério: na Universidade Federal de São Paulo, campus Guarulhos, o curso de Letras possui 4 habilitações: português, inglês, francês e espanhol. Todos os que desejam a habilitação em português precisam fazer o Estágio Supervisionado II. Então, optei por um relatório de estágio de cada habilitação.

O estágio supervisionado nesse curso começa a ser vivenciado pelo aluno/estagiário no $7^{\circ}$. termo, com atividades práticas direcionadas pelas Unidades Curriculares Língua, Literatura e Ensino: Fundamentos I e Estágio Supervisionado Curricular de Língua Portuguesa I, as quais permitem aos alunos realizar trabalhos diretamente nas escolas. No 8 . termo, eles têm a Unidade Curricular Língua, Literatura e Ensino: Fundamentos II e Estágio Supervisionado Curricular de Língua Portuguesa II. Para a licenciatura em Português ainda há o Estágio Supervisionado III.

As Unidades Curriculares Língua, Literatura e Ensino: Fundamentos I e II objetivam ao aluno desempenhar as atividades exigidas durante o estágio, dando subsídios teóricos e reflexivos sobre a relação entre teoria e prática. Além de ir ao campo de estágio, observar essa realidade, o aluno estagiário atua em sala de aula, levando à escola básica os conhecimentos que adquiriu no decorrer do curso e, desse modo, possibilitando aos professores orientadores (aqueles que atuam nas salas de aula do Ensino Fundamental II e Ensino Médio), entrarem em contato com o que está sendo pesquisado na academia no que concerne ao ensino de língua portuguesa. Procura-se estabelecer um diálogo/parceria entre a Universidade e Escola de Educação Básica, mais especificamente, em escolas da região em que está situado o campus da Universidade, as quais são conveniadas com a Universidade, o que significa dizer que o estagiário entra em contato com a realidade escolar da região em que cursa a graduação.

Outro aspecto que merece destaque é o papel do professor orientador da escola enquanto auxiliar do estagiário. É por meio do contato com o professor orientador que o estagiário pode dar início à fase de observação de sala de aula e, assim, encaminha a elaboração do planejamento para a realização do estágio, sempre em diálogo com o professor supervisor, que também é o responsável pela Unidade Curricular Língua, Literatura e Ensino: Fundamentos I e II. 
Entendo que o papel do estagiário é muito mais do que observar ou ministrar aulas. Ele deve ser também um articulador entre universidade e professor orientador, como maneira de incentivar a capacitação docente e possíveis reflexões sobre o ensino de língua materna no Ensino Fundamental e Médio.

\section{0 relatório de estágio e a constituição do ethos discursivos}

Pactuo com a ideia de que a escola desempenha um papel fundamental na formação de uma pessoa. Nela, existe um ambiente que deve mostrar-se como uma forma de proporcionar os mais diversos modos de aquisição do conhecimento e de interação. O docente é um dos principais responsáveis (se não o mais responsável!) nesse processo. O ensino de Língua Portuguesa precisa favorecer o uso da língua no dia a dia dos alunos, em suas práticas sociais, respondendo a diferentes propósitos comunicativos, desenvolvendo a competência comunicativa e considerando as diferentes condições de produção dos discursos. Como afirmam os PCN (1998, p. 34), “(...), os conteúdos de Língua Portuguesa articulam-se em torno de dois eixos: o uso da língua oral e escrita, e a reflexão sobre a língua e a linguagem (...)”. (Sujeito 1, trecho da apresentação/contextualização do relatório).

Neste trecho da introdução do relatório, o enunciador defende a tese de que o professor é um dos principais responsáveis no processo de ensino-aprendizagem de língua portuguesa, o qual deve favorecer o uso da língua(gem) em práticas sociais, a língua em situação de uso, respondendo a diferentes propósitos comunicativos e considerando as diferentes condições de produção de enunciados. O enunciador mostra-se conhecedor da realidade em que está atuando, propondo, inclusive, intervenções para a melhoria da prática pedagógica em língua portuguesa. Mostra-se como autoridade no assunto ao sugerir que o ensino de Língua Portuguesa deve favorecer o uso da língua(gem) em seus diversos usos, o que também corrobora para a construção do ethos discursivo de quem está atualizado em relação à concepção de linguagem que deve nortear o ensino. $\mathrm{O}$ enunciador pauta-se, inclusive, em discursos oficiais, como exemplifica ao mencionar os PCN (1998).

Em outro momento do texto, quando da justificativa do relatório, esse mesmo sujeito (1) apresenta-se, ainda, reflexivo. Ele evidencia o objetivo da escrita do relatório e sua justificativa, deixando claro que, mais que descrever uma experiência, pretende refletir, à luz de pressupostos teóricos visto nas aulas de Fundamentos, sobre a experiência vivenciada no estágio no intuito de contribuir com reflexões da necessidade do diálogo entre universidade e escola básica. Ele argumenta que esse diálogo favorece a superação de muitas das dificuldades encontradas nas duas instituições.

O presente relatório procura descrever e discutir as nossas experiências adquiridas no período de estágio, durante a regência - preparação, realização e avaliação reflexiva. Procuro não apenas descrever as observações e as práticas realizadas na sala de aula, mas também refletir sobre essas abordagens à luz de alguns pressupostos teóricos discutidos, sobretudo, na aula de Fundamentos. Pretendo, ainda, através das abordagens que aqui serão feitas, trazer algumas reflexões para que o ensino de língua materna consiga proporcionar ao estudante da escola básica a capacidade de adquirir novos conhecimentos e de conscientizar-se de seu papel de cidadão, viabilizando as competências a serem desenvolvidas na sala de aula e da necessidade de saber usar a língua(gem) de forma adequada. Essas reflexões também cabem para o aluno universitário que será um futuro professor. (Sujeito 1, apresentação/justificativa, p. 3). 
O enunciador ainda se apresenta como uma autoridade no assunto, assumindo a responsabilidade de refletir sobre o processo de ensino-aprendizagem de língua materna e da própria formação do professor. Demonstra ser um (futuro) professor autônomo, reflexivo, estabelecendo relação entre o estágio supervisionado e as discussões feitas durante as aulas de Fundamentos. Utilizando-se do argumento da superação, esse sujeito mostra que seu relatório não terá apenas um caráter descritivo, documental, mas de reflexão sobre o fazer pedagógico, o que, consequentemente, condiz com a imagem de um profissional da área que, conhecedor da realidade do ensino, busca refletir sobre ela. É possível construir o ethos discursivo de futuro profissional da área, conhecedor do sentido do estágio, atribuindo ao relatório um caráter não meramente descritivo e documental de uma prática.

O sujeito 2 realizou o estágio, na fase de regência, com uma turma do Ensino Médio, mais especificamente com alunos do primeiro ano. Optou pelo trabalho com a literatura. Segundo ele,

Trabalhei com uma turma do primeiro ano do ensino médio. Minha regência abordou o assunto o Arcadismo no Brasil. Apresentei à turma a contextualização histórica, características principais desse movimento, bem como, mostrei aos alunos a importância do movimento na história da literatura brasileira. É importante citar que não me detive somente ao estudo histórico do Arcadismo, foram trabalhados também textos de autores da época, onde (sic) os alunos além de reconhecerem as características principais do movimento e dos autores nesses poemas, faziam também uma análise crítica dos mesmos. Lembrei muito do texto discutido nas aulas de Fundamentos - A literatura é mais que literatura. (Sujeito 2, p. 16).

Ele demonstra sua preocupação com a construção do ethos discursivo pelo seu enunciatário, pois antes que este possa construir uma imagem a seu respeito, por exemplo, a de que sua prática de ensino de literatura se voltou para a historicidade, o que, de acordo com as perspectivas modernas de ensino de literatura, não seria condizente. Ele já desfaz essa possibilidade ao afirmar que não restringiu sua prática somente à história da literatura. $\mathrm{O}$ enunciador procura evidenciar, também, que sua regência atendeu ao solicitado pelo que é proposto na disciplina Fundamentos, quando os futuros professores são orientados sobre a necessidade de estabelecer na relação literatura e ensino uma visão que vá além da história da literatura, inclusive mencionando o nome de um texto que fora discutido na universidade, durante as aulas de Fundamentos. Os professores supervisores, responsáveis pela disciplina, evidenciam a todo instante que é preciso de levar os alunos a refletirem sobre os mecanismos de língua(gem) que permeiam o texto literário e que precisam ser trabalhados na escola básica.

Ao esclarecer como realizou seu trabalho, partindo do argumento da pessoa e sua práticas docentes que valorizam a construção da pessoa vinculada a seus atos, corrobora para a construção de um ethos discursivo coerente em relação à articulação teoria e prática.

O sujeito 3 afirma:

Meu plano de aula, conforme conversado com o professor supervisor Sandro, foi desenvolvido no dia 27 de maio na escola em que eu estagiava. Minha proposta foi explicitar a importância da leitura e da escrita para os alunos. Levei uma atividade que envolvia um gênero discursivo, como sugerem os PCN (1998). Propus o trabalho com o gênero crônica. Primeiro, fizemos a leitura de um texto de Luis Fernando Veríssimo (A velhinha de Taubaté) e depois a proposta era de que os alunos escrevessem uma crônica sobre um fato do cotidiano. Utilizei esse gênero por solicitação da professora-orientadora. Achei a proposta interessante, porque este gênero escrito visa a um fim específico de comunicação, a uma determinada 
situação enunciativa. O gênero crônica é também bem apropriado para trabalhar em sala de aula, pois como, afirma Sá $(1985$, p. 13), "a crônica é denominada de lirismo reflexivo". Para Antonio Candido (2002 p. 43), "é importante mostrar no papel da simplicidade, brevidade e graça próprios da crônica. Os professores tendem muitas vezes a incutir nos alunos uma ideia falsa da serenidade (...). Os elementos constitutivos da crônica são um veículo privilegiado para mostrar de modo persuasivo muita coisa, levando-nos à reflexão" (Procurei levar os alunos a compreenderem principalmente a o funcionamento da linguagem por meio deste gênero. (Sujeito 3, p. 18).

No discurso do sujeito 3, é projetado o ethos discursivo que remete a um profissional que possui autoridade no assunto, embora utilize também do discurso de autoridade para reforçar, ainda, a ideia de que trabalha em conformidade com os teóricos, como exemplifica ao citar autores da área e o próprio documento oficial, no caso, os PCN (1998). Ele defende também essa posição como sendo papel do estagiário assumi-la, o papel de desenvolver um trabalho responsável e coerente no sentido de contribuir para o crescimento dos alunos e contribuir com o trabalho do professor orientador da escola básica. Ele, assim como o sujeito 2, procura levar o enunciador a construir o ethos discursivo de um futuro professor coerente em relação à articulação teoria e prática, ancorado nos pressupostos teóricos da área, preocupam-se especialmente em assumir e apresentar uma prática pautada nos documentos oficiais.

O sujeito 4 afirma, ao trazer algumas reflexões sobre a experiência do estágio na Escola Básica, que:

[...] acreditamos ter contribuído de forma produtiva para o melhoramento do processo ensino e aprendizagem para aquela escola, a partir de uma prática docente atuante e comprometida, objetivando o enriquecimento da aprendizagem de cada educando, valorizando para isso suas experiências e vivências diárias. (sujeito 4, p. 9).

O ethos discursivo do aluno estagiário é praticamente apresentado no próprio discurso, pois além de mostrar, ainda que implicitamente, que sua prática contribuiu para o melhoramento e enriquecimento do processo ensino-aprendizagem do aluno, colocando-a como superior, ainda a caracteriza como atuante e comprometida, uma vez que menciona partir da realidade dos alunos.

\section{Considerações finais}

Considero que o estágio supervisionado curricular seja um importante momento para a formação do professor e para o diálogo da Universidade com a Escola Básica, apesar de ser, ainda, um grande desafio, pois:

(i) trata-se de um momento de estabelecer uma relação de aprendizagem com a escola e não de simplesmente aplicação e,

(ii) precisa ser visto como um espaço para reflexão sobre a formação inicial do futuro professor e da formação continuada do professor orientador, considerando o aspecto dialógico que o estágio pode apresentar.

A partir dos argumentos utilizados pelos enunciadores (sujeitos 1, 2, 3 e 4), é possível perceber que eles apresentam a construção de um relatório de estágio complexo e bem fundamentado, por meio do uso de diversas estratégias e diferentes argumentos, cada qual de acordo com seu estilo, com sua visão sobre o processo de ensino e aprendizagem e relação entre a Universidade e a Escola Básica. Eles não se atêm à mera descrição ou narração das atividades desenvolvidas durante o estágio supervisionado na escola básica. Pelo contrário: 
como foi visto, os sujeitos se posicionam, levando o leitor do relatório a construir o ethos discursivo de futuros profissionais e estudantes comprometidos com a Educação, que procuram relacionar teoria e prática no exercício docente.

No processo de constituição do ethos discursivo, observa-se a recorrência do uso de argumento pragmático e o discurso de autoridade, os quais estão voltados para a pessoa do enunciador, para seus atos, de formas diversas no relatório, a saber:

(i) utilização do argumento pragmático para justificar seus posicionamentos, por meio das relações de causa e efeito;

(ii) uso do argumento de autoridade, recorrendo aos teóricos da área ou aos documentos oficiais.

Partindo do lugar de enunciação dos sujeitos, eles apresentam valores ligados a sua pessoa, a seus atos e dirigem-se ao enunciatário, motivando-os à adesão do ethos discursivo construído. Considerando os possíveis sentidos em relação aos relatórios, temosos relatórios de estágio revelam a constituição do ethos discursivo de um (futuro) profissional da área que articula a relação teoria/prática, conhece e propõe melhorias para a realidade do ensinoaprendizagem, encarando o estágio como um ponto norteador para adquirir conhecimentos sobre o ser professor, sobre sua prática docente no dia a dia da escola básica.

Dada a diversidade de sentidos que emanam dos discursos desses estudantes, apresento aqueles que são mais representativos:

(i) Para o ensino de Língua Portuguesa, os sujeitos não consideram apenas a ótica tradicional, desvinculados dos pressupostos teóricos e oficiais do ensino atuais;

(ii) os sujeitos defendem que o ensino de Língua Portuguesa deve pautar-se nas propostas curriculares dos documentos oficiais (PCN, PCNEM etc.), com ênfase na articulação de seus eixos para o ensino de língua materna e em teóricos da área.

Estes resultados (parciais) estão relacionados à própria organização e sistematização do estágio na Universidade objeto deste estudo, bem como à própria orientação dada para elaboração do relatório de estágio pelos professores supervisores, a qual acontece a partir de diálogo constante, como foi possível perceber nos relatos.

A análise do ethos discursivo de enunciadores em relatórios de estágio nos permite afirmar que os estagiários buscam levar o enunciatário a construir um ethos discursivo que demonstre credibilidade, no intuito de convencer o Outro da capacidade profissional, a partir de uma argumentação que lhes garante o caráter ético e profissional.

Esses resultados corroboram a tese, defendida neste artigo, de que o discurso pedagógico - e mais especificamente o do relatório de estágio, simploriamente ou equivocadamente considerado como mero documento de registro ou como texto meramente descritivo ou relato de atividades desenvolvidas durante o estágio - é constitutivamente marcado pela argumentatividade, que se caracteriza em uma categoria de constituição do ethos discursivo do enunciador.

Os resultados apresentados possibilitam a reflexão para a necessidade de se (re)pensar estratégias a serem desenvolvidas nas Unidades Curriculares dos cursos de formação inicial de professores, com especial atenção para a real função do discurso a ser construído sobre a funcionalidade do estágio supervisionado. A ideia que circula socialmente de que os alunos da universidade pública são bem (in)formados é ratificada nos relatórios de estágio apresentados. O Estágio, nesta Universidade, conforme problematizado neste artigo, não é apenas mais uma atividade curricular, mas o exercício pleno da reflexão sobre a formação inicial e continuada do professor e sua atuação na escola básica. 


\section{Referências}

BRASIL, Secretaria de Educação Fundamental. Parâmetros Curriculares Nacionais terceiro e quarto ciclos do ensino fundamental: língua portuguesa. Brasília: MEC/SEF, 1998. MAINGUENEAU, D. Ethos, cenografia, incorporação. In: AMOSSY, R. Imagens de si no discurso: a constituição do ethos. São Paulo: Contexto, 2005. P. 69-92. . A propósito do ethos. In: Ana Raquel Motta, Luciana, Salgado (Org.) Ethos

discursivo. São Paulo: Contexto, 2008. P. 11-29.

Discurso e Análise do Discurso. São Paulo: Parábola, 2015.

MELO, L. C. de; GONÇALVES, A. V. e SILVA, W. "Escrita acadêmica na escrita reflexiva profissional: citações de literatura científica e relatório de estágio supervisionado" in São Paulo: Bakhtiniana, 8 (1), jan/jun, 2013, p. 95-119.

ORLANDI, E. P. As formas do silêncio - no movimento dos sentidos. Campinas: Editora da Unicamp, 1988.

PACÍFICO, S. M. R. Argumentação e autoria nos escritos de universitários: o discurso sobre alunos de universidades públicas e particulares in Revista Práticas de Linguagem, v. 1, n. 2 jul/dez.2011, p. 103-113.

POSSENTI, S. Ainda sobre a noção de efeito de sentido. In: GREGOLIN, M. do R. V.; BARONAS, R. (Org). Análise do Discurso: as materialidades do sentido. São Paulo: Claraluz, 2001. P. 45-59.

SILVA, W. R. Letramento do professor em formação inicial: interdisciplinaridade no estágio supervisionado da licenciatura. Campinas: Pontes, 2012.

SOUSA, A. P. (Coord.) Projeto de cooperação acadêmica: "Disciplinas da Licenciatura voltadas para o ensino de Língua Portuguesa". São Luís: UFMA/USP/UERN, 2008.

(Financiado pela CAPES/MEC).

Submetido em 26/09/18

Aceito em 10/12/2018 